\title{
Study on the Problems and Countermeasures of the Construction of Primary School Teachers in Sichuan Minority Areas
}

\author{
Quan Jiang ${ }^{1, *}$ \\ ${ }^{1}$ School of Educational Sciences, Sichuan Minzu College, Kangding, Sichuan 626001, China \\ *Corresponding author. Email: jyx_jq@163.com
}

\begin{abstract}
The construction of teaching staff is the key to realize the equalization and modernization of compulsory education in ethnic areas, and is also the inevitable requirement of the development of ethnic basic education in the new era. To improve the quality of basic education, the construction of teachers is the key. Through the investigation of many primary schools in Sichuan minority areas, it is found that there are some problems in the construction of primary school teachers, such as unreasonable establishment standards, prominent structural contradictions, low overall quality and unstable team. Therefore, it is necessary to actively take measures to improve the overall quality of the construction of primary school teachers in ethnic minority areas, such as establishing a unified and reasonable teacher recruitment mechanism, carrying out pairing and Counterpart Assistance between urban and rural areas, promoting the cultivation of local talents, and improving the ability of normal education.
\end{abstract}

Keywords: Ethnic areas, Primary school teachers, Compulsory education, Teaching staff construction.

\section{INTRODUCTION}

Teachers undertake the historical mission of imparting knowledge, spreading culture and inheriting civilization, and shoulder the important task of teaching and educating people. They are not only the first resource for the development of compulsory education in ethnic areas, but also the important cornerstone of local social revitalization, cultural development and people's happiness. The party and the state have always attached great importance to the work of teachers, and have put the construction of teachers in a prominent position, and have issued a series of important measures to strengthen the construction of teachers. "Opinions of the CPC Central Committee and the State Council on comprehensively deepening the reform of the construction of teachers in the new era" points out that "we should comprehensively improve the quality of primary and secondary school teachers and build a high-quality and professional teaching team." The Ministry of Education, the national development and Reform Commission, the Ministry of finance, the Ministry of human resources and social security, and the central editorial office issued the action plan for the revitalization of Teacher Education (2018-2022), which pointed out that "we should improve the supply of teacher resources and promote the fair development of education. We will strengthen teacher training in central and western regions and rural schools, focusing on providing teacher support for targeted poverty alleviation in remote, povertystricken and ethnic minority areas. "China's education modernization 2035" focuses on the deployment of ten strategic tasks for education modernization, one of which is to realize the equalization of basic public education services, improve the equalization level of compulsory education, promote the balanced development of urban and rural compulsory education, and further promote the high-quality balance on this basis.

With the state's strong support for the cause of basic education in ethnic areas, compulsory education in Sichuan Ethnic areas has made great progress, but on the whole, due to "remote areas in ethnic areas, lagging social and economic development, weak and slow development of 
Educational Foundation" [1], there are still many problems in the construction of teachers. In order to understand the current situation of the development of primary school teachers in Sichuan minority areas, and to provide important support for the scientific formulation of primary education professional development plan, clear professional training objectives, reform and improvement of teacher education curriculum system, the author takes some primary schools in Sichuan minority areas as the survey object, through on-the-spot observation, individual interview, questionnaire survey, etc. In order to provide reference for the construction of primary school teachers in minority areas of Sichuan Province, the county has conducted a special investigation and research.

\section{THE CURRENT SITUATION OF THE CONSTRUCTION OF PRIMARY SCHOOL TEACHERS IN SICHUAN MINORITY AREAS}

For a long time, the governments of Maerkang, Jinchuan, Danba and other counties and the education authorities have attached great importance to the construction of the teaching staff, put the construction of the teaching staff on the important agenda, and put it in a prominent position. Proceeding from the reality, in line with the establishment of a sufficient number, high professional quality, reasonable structure, relatively stable and able to adapt to the needs of education, teaching and development of the teaching staff, the government has issued a series of measures On the document of strengthening the construction of teachers, the relevant measures have been formulated, so that the construction of primary school teachers has achieved remarkable results, but the situation of the construction of teachers is still grim, and the existing problems cannot be ignored. This research mainly involves the status of primary school teachers in Sichuan minority areas, the feedback on the evaluation of new primary school teachers, and suggestions on the cultivation of primary school education professionals in Colleges and universities.

From the perspective of educational background, the qualification rate of full-time primary school teachers is $100 \%$, junior college education is $11.5 \%$, undergraduate education is $88.5 \%$, and the proportion of teachers participating in local talent training in Sichuan minority areas is $11.5 \%$.
In terms of age structure, the proportion of primary school teachers under 35 years old is $33.3 \%$ of full-time teachers, the proportion of primary school teachers between 36 and 40 years old is $16.8 \%$, the proportion of primary school teachers between 41 and 45 years old is $16.8 \%$, the proportion of primary school teachers between 46 and 50 years old is $13.9 \%$, and the proportion of primary school teachers between 51 and 54 years old is $5.6 \%$, The proportion of primary school teachers over 55 years old is $2.8 \%$ of full-time teachers.

From the perspective of job structure, the proportion of senior teachers in primary schools is $38.9 \%$ of full-time teachers, the proportion of intermediate professional titles is $36.1 \%$, the proportion of primary professional titles is $16.7 \%$, and the proportion of teachers without professional titles is $8.2 \%$.

From the perspective of discipline structure, there is a shortage of teachers in all disciplines. Among them, primary school English, primary school science, primary school music, primary school physical education and primary school art are the most scarce subjects.

\section{THE MAIN PROBLEMS IN THE CONSTRUCTION OF PRIMARY SCHOOL TEACHERS IN SICHUAN MINORITY AREAS}

\subsection{The Shortage of Primary School Teachers Is Serious}

The standard is unreasonable. In the past, the teacher establishment standards were not in line with the reality of education in ethnic minority areas. They overemphasized scale efficiency and failed to meet the actual needs of educational development. In particular, the primary schools in remote mountainous areas are more prominent. The schools are scattered and the class size is too small. It is impossible to carry out normal teaching work to equip teachers according to the proportion of the establishment. Moreover, the annual natural attrition is about 3-5, which only reduces but does not make up. As a result, there is a large shortage of teachers in local primary schools. In addition, the overall quality of teachers is low, the disciplines are not matched, long-term serious illness, further study, maternity leave and other factors, the actual demand is lower than the actual demand. There are more vacancies. 


\subsection{The Structural Contradiction of Primary School Teachers Is Prominent}

The age structure is unreasonable. $8.3 \%$ of the teachers are over 51 years old. More than $50 \%$ of the existing in-service teachers in some villages and towns are private to public old teachers, with an average age of over 50 years old. In many areas, there are few young teachers under 35 years old in primary schools, and there is a gap between young and middle-aged teachers. The aging of rural teachers is serious. The more remote and poor the rural teachers are, the more serious the aging is. Because young people can't be introduced and can't stay after they go in, only some local private to public teachers can take root in the countryside for a long time. It is worth noting that due to the low birth rate in the agricultural and pastoral areas, with the adjustment of the layout of primary schools, there is not much shortage of primary school teachers in the agricultural and pastoral areas as a whole, and some schools are overstaffed to a certain extent, which makes it difficult for young new teachers to enrich the rural teachers, and the aging phenomenon will continue to aggravate.

The discipline structure is unreasonable. From the perspective of the existing primary school teachers in ethnic areas, there are more teachers in Chinese, mathematics and other subjects, while there are obviously less teachers in music, sports, art, English and other aspects. Due to the lack of teachers, many primary school music, sports and fine arts courses are basically a mere formality. Primary school English is mostly taught by substitute teachers, and the phenomenon of learning is not used widely exists. Even in some township primary schools, the phenomenon of teachers not matching is more common. It is not uncommon for a professional graduate to teach two unrelated subjects. In some schools, although the curriculum is set up according to the regulations of the higher authorities, it is difficult to guarantee the quality of the curriculum.

The regional structure is unbalanced. Due to the unbalanced development of urban and rural education, the concentration of teacher resources in urban areas and towns with good conditions, the overstaffing of teachers in schools with good conditions, and the shortage of teachers in remote rural schools, there is a serious imbalance in the regional distribution of teachers, and there is a prominent contradiction between supply and demand. However, the phenomenon of individual urban teachers applying to teach in rural areas is relatively prominent, and the main reasons are the national treatment, professional title and so on. At the same time, the work pressure of rural teachers is less than that of urban teachers, which is relatively easier than that of urban teachers.

\subsection{The Overall Quality of Primary School Teachers Is Low}

The aging of teachers is becoming more and more obvious, which seriously affects the improvement of the overall quality of teachers. Older age does not reflect the advantage of rich experience, but more shows indifference to education reform, aging knowledge and decline of teaching quality. Many old teachers are not enterprising, their educational ideas are out of date, their teaching methods are backward, and they are lack of innovative consciousness and ability. Due to the aging of their knowledge structure, most of the old teachers feel that they are lack of knowledge and ability, and some of them are in the state of "waiting for retirement".

\subsection{Lack of General Practitioners in Primary Education}

In the recruitment of primary school teachers, the local education authorities lack of knowledge and understanding of primary school education, and only recruit professional teachers according to the disciplines set by primary schools. Primary school education itself is not divided into specific disciplines. Graduates can choose one course from Chinese and mathematics courses to teach, and at the same time, they can also teach other courses according to their own expertise. In the absence of a correct understanding of primary education, most of the local education authorities recruit normal university graduates majoring in Chinese, mathematics and English. Therefore, in many primary schools, new teachers do not adapt to and are not professional in primary education, which will not be conducive to the effective development of primary education.

\subsection{The Basic Skills of New Teachers Are Not Solid}

Most normal students learn professional knowledge in school, and rarely carry out special training on Teachers' skills, which will lead to the lack of basic skills of teachers of many normal students, the theory and practice can not perfectly fit together, and they will encounter many 
difficulties in primary school education and teaching. Because the basic skills are not solid, many new teachers are not willing to write a word on the blackboard. Even when speaking open classes, they seldom write neat writing on the blackboard, which will leave a bad impression on the leaders and will not convince the students. In the actual teaching process, some new teachers are also prone to professional knowledge errors. Now students are involved in a wide range of knowledge. Students think that the new teachers' professional level is not enough and their ability is not enough, which is not conducive to the development of new teachers' teaching work.

\subsection{The Management of Educational Practice in Normal Universities Is Not in Place}

At the present stage, the quality of students' educational practice management in normal universities is not high, which is mainly affected by the students themselves, the management of universities and practice units, resulting in the decline of some students' professional interest, poor development of practical ability, incomplete practice process and other problems. In addition to the pressure of social employment competition, individual interns are busy with various recruitment examinations, resulting in a serious shortage of energy and time investment in educational practice, and a serious lack of educational practice experience.

\section{COUNTERMEASURES AND SUGGESTIONS ON THE CONSTRUCTION OF PRIMARY SCHOOL TEACHERS IN SICHUAN MINORITY AREAS}

From the above analysis, in order to promote the development of compulsory education in ethnic areas as a whole, we must take measures from many aspects to strengthen the construction of teachers.

\subsection{Establishing a Unified and Reasonable Recruitment Mechanism for Primary School Teachers}

When recruiting primary school teachers, the local education bureau and the human resources and Social Security Bureau study policies and take the initiative to introduce (employ) outstanding fresh university graduates with professional counterparts and high comprehensive quality as well as outstanding in-service teachers in the mainland with rich teaching experience and outstanding teaching achievements. [2] We should take full account of the rationality of the structure of teachers, take the compound teachers and primary education major as the key points of recruiting teachers in primary school; continue to recruit the public funded normal students of primary education major to ensure the stability of rural primary school teachers; in the recruitment process, we should not only consider the majors of students, but also comprehensively assess the students' teaching ability and normal skills. In addition, we should improve and implement the corresponding policy mechanism, constantly broaden the channels of teacher training and development, stabilize the existing teachers, and enhance the attraction of normal graduates to teach in underdeveloped minority areas [3].

\subsection{Establishing the System of Urban and Rural Pairing Assistance and Rotation Exchange}

Urban and rural pairing and counterpart assistance activities can be carried out. Formulate relevant policies, organize urban teachers to teach or support in rural weak schools in a planned and phased way, and give rewards and subsidies, or give priority to promotion and evaluation. At the same time, we should also plan to organize rural teachers to exchange learning, investigation and teaching in urban primary schools, resolutely solve the problems faced by the exchange of urban and rural teachers in turn, and organize various forms of teaching and research activities.

\subsection{Vigorously Implementing the Continuing Education Project for Primary School Teachers}

Local education authorities should attach great importance to teacher training, innovate diversified training methods based on reality, formulate teacher training plans step by step and in a planned way, clarify training tasks and requirements, adhere to the combination of long-term training and shortterm training, on-the-job training and off-the-job training, centralized training and decentralized training, online training and offline training, and on-campus and off-campus training We should combine training, adhere to the principle of on-thejob training, self-study as a supplement and short- 
term training as a main part, strive to solve the contradiction between work and study in training, and constantly strengthen the supervision and inspection of training. In addition, we should make full use of the special plan for local talents training in Sichuan minority areas to effectively solve the problem of primary school teachers' academic attainment.

\subsection{Giving Full Play to the Role of Primary School Teachers' Studio}

The Department in charge of education should strengthen the construction and development of the studio of famous teachers in primary schools, and give full play to the demonstration and radiation role of famous teachers in improving teaching skills, scientific research, backbone training, concept guidance, etc. As the administrators of primary schools, they should actively strengthen the selection, training and assessment of key teachers in primary schools. At the same time, they should create a good working environment for the growth of key teachers and effectively solve their difficulties. "We should constantly improve the professional level of rural teachers, strengthen the overall work efficiency of primary school teachers in ethnic areas, so as to promote the balanced development of primary school teachers in ethnic areas under the guidance of the scientific outlook on development" [4].

\subsection{Establishing the Training and Assessment Mechanism of Teachers' Skills}

According to the needs of the reform and development of basic education, we should optimize the curriculum system of teacher education guided by practice, strengthen the training of teaching basic skills and teaching skills such as "pen characters, brush characters, chalk characters and Putonghua", and fully ensure that the teaching practice time of normal students is not less than half a year. Normal colleges and universities should establish an effective training and assessment mechanism for normal students. It is necessary to bring the training of normal basic skills into the course study, to bring the training into the whole process, to strengthen the guidance, and to implement the system of all staff assessment and certification.

\subsection{Strengthening the Management of Normal Students' Educational Practice}

Normal colleges and universities should focus on the supervision and management of normal students' educational practice, select the instructors inside and outside the school, keep in touch and communicate with the receiving school and the instructors at any time, go to the practice school regularly or irregularly to check the situation of normal students' educational practice, and discuss with the instructors, administrators and students in the practice school, so as to solve the problems in educational practice In order to improve the students' practical ability of education.

\section{CONCLUSION}

The construction of teaching staff is a complex system engineering, which is influenced by many factors. Local education administrative departments should not only do a good job in the overall planning of the construction of primary school teachers, but also pay attention to the professional development and training of primary school teachers in the new era, consider the pre service, secondary and post service training as a whole, and highlight the ability training of modern educational technology. Fully understand the actual development status and ability of excellent primary school teachers in ethnic areas, improve teachers' practical ability from theory, practice and many aspects and angles, and strengthen primary school teachers in ethnic areas.[5]In addition, we need to deepen the training of bilingual teachers. All kinds of normal universities at all levels and continuing education training institutions should consider the particularity of the development of compulsory education in Sichuan minority areas, correctly position the training objectives, strengthen the curriculum reform of teacher education, attach importance to the cultivation of national education feelings and professional ability of normal students, and enhance the adaptability of normal students' work. The administrators of primary schools in Sichuan minority areas should create a good working and learning environment for the growth and development of teachers at all levels, strengthen post management, and establish an incentive mechanism. In a word, the local education administrative departments should reasonably arrange the employment index according to the local teachers' demand and the information of talent flow in the whole province; when formulating the enrollment plan or providing employment 
guidance, the normal universities should also refer to the regional differences and changing trend of the number of compulsory education teachers in the whole province, so as to improve the pertinence of the enrollment plan and the employment rate of graduates. [6] We should start from the two aspects of new teacher training and in-service teacher training, innovate the mechanism and mode, take effective measures, strive to improve the quality and ability of teachers, vigorously strengthen the construction of primary school teachers in Sichuan minority areas, strive to improve the quality of education, and strive to consolidate the foundation of poverty alleviation and construction and development of education.

\section{AUTHORS' CONTRIBUTIONS}

This paper is independently completed by Quan Jiang.

\section{REFERENCES}

[1] Xia Maolin, Gao Mengyi. On the Construction of Rural Primary School Teachers in Ethnic Minority Areas - a Case Study of Sichuan Tibet Yi Area[J].Journal of Lingnan Normal University, 2018 (2): 28.

[2] Ma Hongjiang, Chen Song, Huang Xinjian. Problems and Countermeasures of rural education in ethnic minority areas of Sichuan Province -- Investigation Report on Rural Education in markang County[J].Achievements of National Teacher Research Fund during the Eleventh Five Year Plan period (Sichuan volume), 2010. (05): 1246.

[3] An Yan. Research on the Problems and Countermeasures of teacher Team Construction in Underdeveloped Minority Areas [J]. Heilongjiang Higher Education Research, 2015 (12): 99.

[4] Pang Mei. Some Thoughts on the Construction Of Primary School Teachers in Ethnic Areas $[\mathrm{J}]$. China Ethnic Education, 2014 (12): 31.

[5] Chen Meiqin. Exploration on the cultivation of practical ability of excellent primary school general practitioners in ethnic minority areas under the background of "Internet + education" [J]. Education and teaching forum, 2020 (46): 47.
[6] Zhou Hong, Tang Zhibin. Analysis on the demand characteristics of compulsory education teachers in Sichuan before 2020 [J]. Jin Tian, 2013 (02): 159. 